\title{
Prevalence of Type 2 Diabetes Mellitus Among Urban Bihari Communities in Dhaka, Bangladesh: A Cross-sectional Study in a Minor Ethnic Group
}

Muhammad Asaduzzaman ${ }^{1}$, Shahanaz Chowdhury ${ }^{2}$, Jahid Hossen Shahed ${ }^{3}$, Mohammad Abdullah Heel Kafi ${ }^{4}$, Md. Nazim Uzzaman ${ }^{5}$, Mahfuza Talukder Flowra ${ }^{6}$, MSA Mansur Ahmed ${ }^{7}$

1. Epidemiology and Public Health, International Center for Diarrhoeal Disease Research, Dhaka, BGD 2. Department of Community Health, Bangladesh University of Health Sciences, dhaka,bangladesh 3.

Consultant, United Nations Children's Fund, Dhaka, Bangladesh 4. Infectious Diseases Division, International Centre for Diarrhoeal Disease Research Bangladesh (icddr,b) 5. Epidemiology and Public Health, International Centre for Diarrhoeal Disease Research, Dhaka, BGD 6. Faculty of Medicine, Universitas Gadjah Mada,indonesia 7. Department of Community Medicine, Bangladesh University of Health Sciences, dhaka,bangladesh

$\square$ Corresponding author: Muhammad Asaduzzaman, asaduzzaman@icddrb.org Disclosures can be found in Additional Information at the end of the article

\section{Abstract}

\section{Introduction}

The prevalence, disease progression, and treatment outcomes for patients with type 2 diabetes vary significantly between ethnic groups. The Bihari community constitutes one of the most vulnerable populations in Bangladesh on the basis of access to health services and other fundamental rights. Our study aimed at finding out the prevalence and risk factors of type 2 diabetes among the Bihari adults in Dhaka city.

\section{Methods}

This cross-sectional community-based study was carried out among stranded Pakistanis (known as Bihari) living in camps in the Mirpur area from July 2014 to June 2015. Laboratory-based oral glucose tolerance test (OGTT) was the basis for the diagnosis of type 2 diabetes mellitus (DM). Anthropometric measurements, blood pressure, biochemical tests, family history, and socioeconomic information were obtained to determine the risk factors.

\section{Results}

Received 01/09/2018

Review began 01/11/2018 Review ended 01/15/2018 Published 01/26/2018

C Copyright 2018

Asaduzzaman et al. This is an open access article distributed under the terms of the Creative Commons Attribution License CC-BY 3.0., which permits unrestricted use, distribution, and reproduction in any medium, provided the original author and source are credited.
The prevalence of diabetes mellitus (DM), impaired glucose tolerance (IGT), and impaired fasting glucose (IFG) were estimated at $10.11 \%, 8.74 \%$, and $4.55 \%$, respectively. Increased diastolic blood pressure, serum triglyceride, and cholesterol level were observed to be significantly $(p<0.05)$ associated with diabetes. Also, the presence of diabetes, high blood pressure, and obesity among relatives significantly increased the probability of diabetes.

\section{Conclusions}

To the best of our knowledge, this is the first study on diabetes prevalence among the Bihari community in Bangladesh. The prevalence of type 2 diabetes mellitus was found to be higher among the Bihari community compared to the general population in Bangladesh. Health planners and policymakers should realize the alarming situation and identified risk factors and consider the minor ethnic groups during decision-making regarding prevention and control of diabetes and other noncommunicable diseases.

How to cite this article

Asaduzzaman M, Chowdhury S, Shahed J, et al. (January 26, 2018) Prevalence of Type 2 Diabetes

Mellitus Among Urban Bihari Communities in Dhaka, Bangladesh: A Cross-sectional Study in a Minor

Ethnic Group. Cureus 10(1): e2116. DOI 10.7759/cureus.2116 
Categories: Preventive Medicine, Endocrinology/Diabetes/Metabolism, Epidemiology/Public Health Keywords: diabetes, bihari community, ethnicity, urban, bangladesh

\section{Introduction}

Diabetes is one of the four major types of noncommunicable diseases (NCDs) that make the largest contribution to morbidity and mortality worldwide [1]. In 2016, about 422 million people globally had diabetes, with most living in the developing countries, and unfortunately, more than $80 \%$ of diabetes deaths occur in low- and middle-income countries [2]. The prevalence of diabetes is increasing in Bangladesh in both urban and rural areas. A recent scoping review (1994-2013) revealed that the prevalence of type 2 diabetes varied from $4.5 \%$ to $35.0 \%$ in Bangladesh [3]. The overall age-adjusted ( $\geqslant 35$ years) prevalence of diabetes was estimated as $9.7 \%$, based on Bangladesh Demographic and Health Survey (BDHS) 2011 data [4].

A recent population-based study on the Santhal tribe (an ethnic group) of Bangladesh published in 2014 revealed that the prevalence of type 2 diabetes mellitus (DM) was only $0.6 \%$ and hyperglycemia (fasting plasma glucose $>5.5 \mathrm{mmol} / \mathrm{l}$ ) was $10 \%$ [5]. The reason behind these insulin resistance phenomena is not straightforward. Multidimensional risk factors are associated with type 2 diabetes, namely modifiable and non-modifiable risk factors like obesity, physical inactivity, sedentary lifestyle, and gender, age, environmental influence etc., respectively. There is evidence to suggest that the prevalence, disease progression, and treatment outcomes for people with type 2 diabetes vary significantly between ethnic groups [6].

The Bihari people in Bangladesh, also known as non-Bangladeshi or stranded Pakistanis, are an ethnic minority, and at present over 250,000 Biharis live in 66 squalid refugee camps across the country [7]. They are still culturally isolated and speak their native Urdu. The slum-like camps are overcrowded with a very negligible population (less than 5\%) having formal education [8]. The vulnerability of this community regarding access to essential healthcare services and other fundamental rights may force them to adopt different ecological conditions, which is reflected through potential differences in socio-economic and demographic condition. To our knowledge, no study has been conducted to describe diabetes among the Bihari communities in Bangladesh. Our study aimed at finding out the prevalence and the risk factors of type 2 diabetes among the Bihari adults ( $\geqslant 30$ years) in Dhaka city.

\section{Materials And Methods}

\section{Study design}

This was a cross-sectional community-based study carried out from July 2014 to June 2015.

\section{Study settings, sample size, and study population}

The study was carried out among the Bihari communities living in the Mirpur area of Dhaka North City Corporation (DNCC). Apparently healthy adult volunteers of the seven camps (named as Talat camp, Millat camp, Consol camp, Irani camp, Kashmiri camp, Madrasa camp, and Rahamat camp) of the study area were randomly selected as study participants.

The calculated sample size was 284 by considering the prevalence rate at $6.1 \%$ of type 2 diabetes mellitus among the general population of Bangladesh [9] and error=0.057. As the study population were camp dwellers with very low or no chance of migration, we considered $<1 \%$ drop out, and therefore we included 286 participants in our study.

\section{Inclusion Criteria}

People (both males and females) aged $\geqslant 30$ years who agreed to participate voluntarily were selected as study participants. 
Subjects aged $<30$ years and not willing to participate were excluded from the study.

\section{Data collection procedure}

Four trained data collectors were assigned to prepare a list of eligible subjects ( $\geqslant 30$ years) of the selected camps. After random selection of the participants from the camp dwellers' list, written informed consents were taken from each individual and they were given a study-specific identification number and card. Face-to-face interviews were conducted using pretested semistructured questionnaires, and each interview session took around 45 minutes. Nutritional status was assessed by anthropometric measurement of weight, height, hip and waist circumference. Basic information such as age, sex, educational status, occupation, family income, food intake pattern, smoking and alcohol consumption history as well as information about the various factors that affect the blood glucose level were also collected. During the interview, the participants were requested to provide a sample for measuring their blood glucose level using the oral glucose tolerance test (OGTT) and lipid profile on a specific date with clear instruction. All tests were performed in the biochemistry laboratory of the Bangladesh Institute of Health Sciences (BIHS) and the study participants were informed about the test results. The data were checked meticulously after collection to avoid errors or inconsistencies.

\section{Data analysis}

Data analysis was performed using Stata 13 (StataCorp LP, Texas, USA). The prevalence rate of diabetes was determined by percentage. Values were reported as the mean \pm standard deviation (SD). Statistical comparisons between different groups were made using the $t$-test and $\chi^{2}$ test. Logistic regression was applied to calculate the crude odds ratio and adjusted odds ratio to identify risk factors. Stepwise model selection using the Akaike information criterion (SWAIC model) [10] was used to get the significant risk factors. A p-value of $<0.05$ was considered statistically significant.

\section{Operational definitions}

The World Health Organization (WHO) 2006 criteria [11] were followed to measure the parameters.

\section{Diabetes Mellitus (DM)}

It has been determined by measuring the venous plasma glucose level by OGTT at 0 minute and 120 minutes. If the 0 minute glucose level is $\geqslant 7.0 \mathrm{mmol} / \mathrm{l}$ and the 120 minute glucose level is $\geqslant 11.1$ $\mathrm{mmol} / \mathrm{l}$, the person is considered as diabetic.

Impaired Glucose Tolerance (IGT)

It has been determined if the 0 minute glucose level is $<7.0 \mathrm{mmol} / \mathrm{l}$ and the 120 minute glucose level is between 7.8 to $<11.1 \mathrm{mmol} / \mathrm{l}$.

Impaired Fasting Glucose (IFG)

When the 0 minute glucose level is 6.1 to $<7.0 \mathrm{mmol} / \mathrm{l}$ and the 120 minute glucose level is $<7.8$ $\mathrm{mmol} / \mathrm{l}$.

Normal Glucose Tolerance (NGT)

If the 0 minute glucose level is $<6.1 \mathrm{mmol} / \mathrm{l}$ and 120 minute glucose level is $<7.8 \mathrm{mmol} / \mathrm{l}$.

Ethnicity 
A complex multidimensional construct reflecting the confluence of the biological factors and geographical origins, culture, economic, political and legal factors, as well as racism [12].

Anthropometric Assessment

The measurement of the physical dimension and the gross composition of the body. In this study, the body mass index (BMI) and waist-hip ratio (WHR) have been used.

Body Mass Index (BMI)

It is calculated by the formula: weight in kilogram divided by height in meter squared. It helps to grade the obesity. A BMI $\geqslant 25$ is graded as overweight.

Hypertension (HTN)

Defined as a systolic blood pressure of $\geqslant 140 \mathrm{~mm} \mathrm{Hg}$ and/or diastolic blood pressure of $\geqslant 90 \mathrm{~mm} \mathrm{Hg}$.

Lipid Profile

Based on the criteria described by ES Ford et al. [13].

Hypercholesterolemia

Fasting venous blood cholesterol level $\geqslant 200 \mathrm{mg} / \mathrm{dl}$.

Triglycerides Level

Fasting venous blood triglycerides level considered abnormal if it is $>150 \mathrm{mg} / \mathrm{dl}$.

Total Monthly Income

It includes pay and allowances drawn by the respondent plus any income from other family members.

Vigorous Intensity Physical Activities

Activities that require hard physical effort and cause large increases in respiratory or heart rate.

Moderate Intensity Physical Activities

Activities that require moderate physical effort and small increases in respiratory or heart-rate.

Sedentary/Mild Intensity Physical Activities

Sitting or reclining at work, at home, getting to and from places, or with friends, including time spent sitting at the desk, sitting with friends, traveling in the car, bus, train, reading, playing cards, or watching television, but not including time spent sleeping.

\section{Results}

\section{Sociodemographic information}

The mean age of the male subjects was 47.7 years and that of the female participants was 41.8 years, whereas about $41 \%$ of the total study participants were between $30-39$ years of age. There were no 


\section{Cureus}

formal years of schooling among $85 \%$ of the participants. The types of occupation varied among the participants. Most of the male respondents (60\%) were involved in business, whereas the females were mostly (61\%) engaged in household activities. Monthly income ranged between Bangladeshi Taka (BDT) 5001 to 10,000 for more than half of the respondents. However, monthly income $\leqslant 5000$ BDT constituted about $30 \%$ of the study population, which indicates low socioeconomic status (Table 1). 


\section{Cureus}

\section{Variables}

Sex

groups in years

$30-39$

$40-49$

$50-59$

$\geq 60$

Mean age

\section{Education}

Illiterate

Primary

Secondary

Higher secondary

Occupation

Domestic work

Business

Service holder

Day laborer

Others

Monthly income (BDT)

$$
\leq 5000
$$

5001-10,000

$10,001-15,000$

$15,001-20,000$

$>20,000$

$\begin{array}{ll}17 & 26.15 \\ 18 & 27.69 \\ 19 & 29.23 \\ 11 & 16.92\end{array}$

47.7

54

83.07

9.23

3.08

4.62

3.08

60.00

15.38

9.23

12.31

27.7

55.4

10.8

6.2

0
Percentage

Total

Percentage

Female

$N=221$

77.27

$N=286$

$\begin{array}{lll}44.80 & 116 & 40.56 \\ 33.94 & 93 & 32.52 \\ 10.86 & 43 & 15.03 \\ 10.41 & 34 & 11.89\end{array}$

41.8

188

85.07

242

84.62

22

9.95

28

9.79

8

3.62

3.50

3

1.36

2.10

6

135

61.09

137

47.90

57

25.79

96

33.57

3

1.36

13

4.55

0

0

6

2.10

26

11.76

34

11.89

TABLE 1: Distribution of the respondents according to demographic characteristics.

82.80 Bangladeshi Taka (BDT) $=1$ United States Dollars (USD).
Lifestyle, family history, clinical, and anthropometric measurements 


\section{Cureus}

Most of the participants (76\%) were engaged in moderate physical activities. Smoking habit among the males and females was $71 \%$ and $32 \%$, respectively. Around $20 \%$ of the male respondents used to consume alcohol (Table 2). Almost $50 \%$ of the enrolled participants had a positive family history of $\mathrm{DM}$, of which first (1st) and second (2nd) degree relatives account for $36 \%$ and $14 \%$, respectively (Table 3). The BMI was found to be significantly (p-value $<0.05$ ) higher among the female participants compared to the male participants (Table 4).

\begin{tabular}{|c|c|c|c|c|c|c|}
\hline \multirow[t]{2}{*}{ Characteristics } & Male & Percentage & Female & Percentage & Total & Percentage \\
\hline & $N=65$ & 22.73 & $N=221$ & 77.27 & $N=286$ & \\
\hline \multicolumn{7}{|l|}{ Physical activities } \\
\hline Vigorous intensity & 4 & 6.15 & 0 & 0 & 4 & 1.40 \\
\hline Moderate intensity & 47 & 72.30 & 169 & 76.48 & 216 & 75.52 \\
\hline Vigorous + moderate intensity & 7 & 10.77 & 14 & 6.33 & 21 & 7.34 \\
\hline Mild intensity & 7 & 10.77 & 38 & 17.19 & 45 & 15.74 \\
\hline \multicolumn{7}{|l|}{ Smoking habit } \\
\hline Yes & 46 & 70.77 & 71 & 32.13 & 117 & 40.91 \\
\hline No & 19 & 29.23 & 150 & 67.87 & 169 & 59.09 \\
\hline \multicolumn{7}{|l|}{ Alcohol consumption } \\
\hline Yes & 13 & 20 & 1 & 0.45 & 14 & 4.90 \\
\hline No & 52 & 80 & 220 & 99.55 & 272 & 95.10 \\
\hline
\end{tabular}

TABLE 2: Distribution of the respondents according to lifestyle or behavioral characteristics. 


\section{Cureus}

\begin{tabular}{|c|c|c|c|c|c|}
\hline Variables & & Percentage & & Percentage & \\
\hline \multirow[t]{2}{*}{ Sex } & Male & & Female & & Total \\
\hline & $N=65$ & 22.73 & $N=221$ & 77.27 & IV \\
\hline
\end{tabular}

Presence of diabetes mellitus among relatives

$\begin{array}{llllllr}1^{\text {st }} \text { degree relatives } & 9 & 13.85 & 94 & 42.53 & 103 & 36.01 \\ 2^{\text {nd }} \text { degree relatives } & 6 & 9.23 & 33 & 14.93 & 39 & 13.64 \\ \text { No } & 33 & 50.77 & 30 & 13.57 & 63 & 22.03 \\ \text { Does not know } & 17 & 26.15 & 64 & 28.96 & 81 & 28.32\end{array}$

Presence of relative having high blood pressure

$\begin{array}{lcccccr}1^{\text {st }} \text { degree } & 14 & 21.54 & 36 & 16.29 & 50 & 17.48 \\ 2^{\text {nd }} \text { degree } & 13 & 20 & 38 & 17.19 & 51 & 17.83 \\ \text { No } & 25 & 38.46 & 90 & 40.72 & 115 & 40.21 \\ \text { Does not know } & 13 & 20 & 57 & 25.79 & 70 & 24.48\end{array}$

Presence of relative who has obesity

$\begin{array}{lllllll}1^{\text {st }} \text { degree } & 7 & 10.77 & 37 & 16.74 & 44 & 15.38 \\ 2^{\text {nd }} \text { degree } & 5 & 7.69 & 28 & 12.67 & 33 & 11.54 \\ \text { No } & 48 & 73.85 & 142 & 64.25 & 190 & 66.43 \\ \text { Does not know } & 5 & 7.69 & 14 & 6.33 & 19 & 6.64\end{array}$

TABLE 3: Distribution of the respondents according to family history. 


\section{Cureus}

\section{Variables}

Sex

Anthropometric variables

Height (cm)

Weight $(\mathrm{kg})$

Waist circumference $(\mathrm{cm})$

Body mass index (BMI)

Waist to hip ratio (WHR)

Clinical variables

Systolic blood pressure $(\mathrm{mm} \mathrm{Hg})$

Diastolic blood pressure (mm Hg)

Fasting blood glucose (FBG) $\mathrm{mmol} / \mathrm{l}$

Oral glucose tolerance test (OGTT) mmol/l

Cholesterol

Triglyceride
$160.49(7.30)$

$57.91(11.44)$

$81.53(12.16)$

$22.50(4.26)$

$0.92(0.13)$

$114.10(22.74)$

$71.46(10.61)$

$4.75(0.19)$

$6.33(0.33)$

$127.67(4.75)$

$125.23(11.70)$
$P$ value

Female $(\mathrm{N}=221)$

Mean (SD)

$148.70(8.68)$

0.000

$56.73(13.49)$

0.477

$88.24(25.31)$

0.039

$25.67(5.15)$

0.000

$0.93(0.11)$

0.653

0.698

0.489

0.165

0.108

0.057

0.292

TABLE 4: Distribution of the respondents according to mean values (standard deviation (SD) for anthropometric and clinical variables.

\section{Prevalence of type 2 diabetes}

The overall prevalence of type 2 diabetes, impaired glucose tolerance, and impaired fasting glucose was estimated at $10.11 \%, 8.74 \%$, and $4.55 \%$, respectively. Increased diastolic blood pressure, serum triglyceride, and cholesterol level were observed to be significantly ( $\mathrm{p}$-value $<0.05$ ) associated with diabetes (Table 5). 


\section{Cureus}

\begin{tabular}{|c|c|c|c|c|c|c|c|c|}
\hline \multirow[t]{2}{*}{ Variables } & NGT & P-value & IFG & P-value & IGT & P-value & DM & P-value \\
\hline & No. (\%) & & No. (\%) & & No. (\%) & & No. (\%) & \\
\hline Total respondents & $221(77.27)$ & \multirow{3}{*}{0.204} & $13(4.55)$ & \multirow{3}{*}{0.518} & $25(8.74)$ & \multirow{3}{*}{0.874} & $29(10.11)$ & \multirow{3}{*}{0.093} \\
\hline Male & $54(18.88)$ & & $2(0.70)$ & & $6(2.10)$ & & $3(1.05)$ & \\
\hline Female & 167 (58.39) & & $11(3.85)$ & & $19(6.64)$ & & $26(9.09)$ & \\
\hline Raised body mass index & 102 (35.66) & 0.662 & $8(2.80)$ & 0.277 & $8(2.80)$ & 0.119 & $17(5.94)$ & 0.18 \\
\hline Increased waist to hip ratio & $34(11.89)$ & 0.243 & $3(1.05)$ & 0.534 & $6(2.10)$ & 0.312 & $5(1.75)$ & 0.944 \\
\hline High systolic blood pressure & 17 (5.94) & 0.129 & $2(0.70)$ & 0.419 & $3(1.05)$ & 0.596 & $4(1.40)$ & 0.353 \\
\hline High diastolic blood pressure & 0 & 0.065 & 0 & 0.827 & 0 & 0.757 & $1(0.35)$ & 0.003 \\
\hline Increased triglyceride & $53(18.53)$ & 0 & $9(3.15)$ & 0.002 & $7(2.45)$ & 0.813 & 19 (6.64) & 0 \\
\hline Hypercholesterolemia & $26(9.09)$ & 0 & $6(2.10)$ & 0.003 & $2(0.70)$ & 0.249 & $13(4.55)$ & 0 \\
\hline
\end{tabular}

TABLE 5: Distribution of overweight, hypertension, and hyperlipidemia among the respondents in different categories of glucose tolerance.

Abbreviations- SBP: systolic blood pressure; DBP: diastolic blood pressure; IFG: impaired fasting glucose; IGT: impaired glucose tolerance; DM: diabetes mellitus.

\section{Risk factors for diabetes}

The crude and adjusted odds ratio for factors affecting diabetes was determined by applying logistic regression. When the risk factors were calculated individually based on the DM positivity, no risk factor was recorded to be statistically significant, which meant that there might have been the confounding effect of other factors. However, when all the risk factors obtained from the current study were adjusted by the respondent's smoking habit, drinking habit, the presence of high blood pressure (BP), moderate intensity activity, and use of salt in regular meals, it was observed that the presence of relatives with diabetes, high blood pressure, and obesity significantly affected the probability of type 2 diabetes (Table 6 ). 


\section{Cureus}

\begin{tabular}{|l|llllll|}
\hline & Crude & & \multicolumn{5}{l|}{ Adjusted } \\
\hline & $\begin{array}{l}\text { Odds } \\
\text { ratio }\end{array}$ & $\begin{array}{l}\text { P- } \\
\text { value }\end{array}$ & $\begin{array}{l}\text { Confidence } \\
\text { interval }\end{array}$ & $\begin{array}{l}\text { Odds } \\
\text { ratio }\end{array}$ & P- value & Confidence interval \\
Relative with diabetes mellitus & 1.558 & 0.098 & $0.922,2.637$ & 2.16 & 0.027 & $1.091,4.277$ \\
Relative with high blood pressure & 0.659 & 0.149 & $0.374,1.161$ & 0.39 & 0.025 & $0.174,0.891$ \\
Relative with obesity & 1.109 & 0.705 & $0.648,1.898$ & 2.23 & 0.030 & $1.081,4.608$ \\
Smoking & 0.871 & 0.731 & $0.395,1.918$ & 2.24 & 0.127 & $0.794,6.323$ \\
Involved in moderate activity & 0.614 & 0.295 & $0.246,1.529$ & 0.78 & 0.708 & $0.223,2.767$ \\
Previous history of high blood & 1.498 & 0.383 & $0.604,3.721$ & 1.61 & 0.424 & $0.497,5.267$ \\
pressure & 1.003 & 0.995 & $0.394,2.554$ & 1.31 & 0.489 & $0.607,2.836$ \\
Consumption of alcohol & 0.942 & 0.875 & $0.445,1.992$ & 1.02 & 0.971 & $0.364,2.853$ \\
Regularly using salt to meals & & & & & & \\
\hline
\end{tabular}

\section{TABLE 6: Distribution of the different risk factors among the respondents.}

Observed as significant risk factors for diabetes mellitus (DM) after stepwise model selection using Akaike information criterion [10].

\section{Discussion}

Differences in the prevalence, risk factors, and other adverse health conditions among specific population groups exist in type 2 diabetes mellitus throughout the world. There are multiple factors that contribute to these disparities, including biological, clinical, health system, and social factors [14]. Our study findings regarding type 2 diabetes prevalence and the risk factors among the Bihari population in Bangladesh have resemblance with similar studies [15]. In our study, the prevalence of diabetes was estimated higher in the 40-49 years age group in males and 50-59 years age group in females, which is consistent with previous study findings for developing countries that most people with diabetes are aged between 45 and 64 years [16]. Population below 45 years of age may be included due to distribution of the study population.

There is an inverse association between socioeconomic status and the prevalence of type 2 diabetes in the middle years of life [17]. A study conducted in the United States of America revealed that diabetes was over twice as prevalent among African-Americans (10.3\%) when compared to Whites $(4.6 \%$; odds ratio $(\mathrm{OR})=2.38 ; 95 \%$ confidence interval $(95 \% \mathrm{CI}): 1.50,3.75 ; \mathrm{P}=0.0001)$. This finding suggests that exposure to factors that contribute to the causation of diabetes is more common in deprived areas, as well as has racial difference [18].

Most studies reported a twofold to sixfold increased risk of type 2 diabetes associated with a positive family history compared to a negative family history of diabetes. These estimates are consistently elevated across different study designs and in several ethnic groups [19]. Our study also supports these data and exhibits a significant relationship between diabetes and positive family history of DM, hypertension, and obesity. Relevant nutritional measurements like BMI, waist to hip ratio (WHR) taken from the study population were found very much related to the causation of DM. The American Diabetes Association (ADA) recognizes BMI $\geqslant 25 \mathrm{~kg} / \mathrm{m} 2$ as a risk factor for type 2 diabetes [20]. In our study, 102 subjects (35\%) were overweight. Among the overweight population, 33 subjects (32\%) had abnormal glucose metabolism, which includes 17 diabetic, eight IGT, and eight IFG cases. Therefore, among the diabetic cases, $58 \%$ had BMI $\geqslant 25 \mathrm{~kg} / \mathrm{m} 2$. Two national surveys 
conducted by Bays et al. [21] revealed that increased BMI was associated with the increased prevalence of diabetes mellitus, hypertension, and dyslipidemia, and more than $75 \%$ of the patients had BMI $\geqslant 25 \mathrm{~kg} / \mathrm{m} 2$. Although, the BMI rate was found a bit lower, which may be due to the lesser sample size and differences in the background information of the participants of the two studies. Furthermore, 48 participants (17\%) had an abnormal waist-hip ratio, of which $29 \%$ was suffering from either DM or glucose intolerance, which reinforces the previous findings that increased WHR is closely associated with increased risk of type 2 diabetes [22].

Minorities commonly live in substandard neighborhood environments with the lack of healthy food stores, lack of places to exercise, and increased psychosocial stressors related to crime or limited social cohesion that results in poor health outcomes [23-24]. Evidence from the multiethnic study of atherosclerosis found that inferior neighborhoods were associated with increased smoking, physical inactivity, and poorer control of blood pressure, which can contribute to the development of diabetes and its complications [25]. More than 30\% of our study subjects were found to have an increased serum triglyceride level, out of which 35 subjects (40\%) had abnormal glucose metabolism. It again established the link between glucose and lipid metabolism.

But hypercholesterolemia was less evident both in the diabetic and normoglycaemic subjects. Only 47 (16\%) people had a higher cholesterol level, of which 13 participants were diabetic.

Hypertriglyceridemia, reduced high-density lipoprotein (HDL), and increased low-density lipoprotein (LDL) particles characterize dyslipidemia, which is a risk factor for coronary artery disease (CAD), dyslipidemia, hypertension, stroke, and type 2 diabetes [26].

About $41 \%$ of the respondents in our study were known to be smokers. It was alarming that $32 \%$ female participants gave the history of tobacco consumption. Although we did not find a significant association between smoking and diabetes, previous study findings showed that diabetes incidence was higher among smokers who used to smoke cigarettes $\geqslant$ two packs/day compared to those who had never smoked [27]. Considering the social and religious aspect of the study population in Bangladesh, the alcohol consumption seems to be high among the respondents ( $5 \%$ of the total participants). Alcohol intake was found to be associated with the risk of non-insulin-dependent diabetes mellitus, especially in men [28]. Numerous studies have found a contrary relationship between type 2 diabetes and education, occupation, and income that is consistent across all adult age groups. In our study, the literacy rate was found to be very poor among Bihari communities where $85 \%$ of the total population had no formal education. More than a quarter of the study participants had a monthly income $\leqslant 5000$ BDT. Robbins et al. found that diabetes prevalence is more strongly associated with poverty [29]. Health care access and health insurance are important factors that allow patients with diabetes to receive adequate medical care.

The findings of this study may not be generalizable to all ethnic communities or the whole Bihari population in Bangladesh as the data was collected only from Dhaka city. Therefore, the prevalence and risk factors for diabetes might not be similar among the other Bihari camp residents in different parts of the country. As self-reported information was collected from the patients, there might be a chance of interviewer bias and recall bias. Other limitations include small sample size, crosssectional study design, and the lack of follow-up, though we made suggestions to the respondents with positive findings to consult with clinicians.

\section{Conclusions}

The Bihari community constitutes one of the most vulnerable populations in Bangladesh on the basis of access to health care services and other fundamental rights. This study reveals the high prevalence of type 2 diabetes mellitus among the Bihari communities compared to the general population. Health planners and policymakers should realize the alarming situation and identified risk factors and should consider the minority ethnic groups during decision-making regarding prevention and control of diabetes and other noncommunicable diseases.

\section{Additional Information}




\section{Disclosures}

Human subjects: Consent was obtained by all participants in this study. Institutional review board of the Bangladesh Institute of Research and Rehabilitation for Diabetes, Endocrine and Metabolic Disorders (BIRDEM) issued approval N/A. The study was reviewed and approved by the institutional review board of the Bangladesh Institute of Research and Rehabilitation for Diabetes, Endocrine and Metabolic Disorders (BIRDEM) and had therefore been performed in accordance with the ethical standards of the Declaration of Helsinki. Written informed consent has been obtained from all study subjects prior to their inclusion in the study. Animal subjects: All authors have confirmed that this study did not involve animal subjects or tissue. Conflicts of interest: In compliance with the ICMJE uniform disclosure form, all authors declare the following: Payment/services info: All authors have declared that no financial support was received from any organization for the submitted work.

Financial relationships: All authors have declared that they have no financial relationships at present or within the previous three years with any organizations that might have an interest in the submitted work. Other relationships: All authors have declared that there are no other relationships or activities that could appear to have influenced the submitted work.

\section{Acknowledgements}

The study was supported by Norad's Programme for Master Studies; Grant no. NOMA/NFP 20062014. We would like to thank the study participants for their cordial cooperation during the study.

\section{References}

1. Global action plan for the prevention and control of noncommunicable diseases 2013 - 2020 . WHO library cataloguing-in-publication data. 2013, Accessed: January 11, 2018:

http://apps.who.int/iris/bitstream/10665/94384/1/9789241506236_eng.pdf.

2. World Health Day 2016: beat diabetes . (2016). Accessed: January 11, 2018: http://www.who.int/campaigns/world-health-day/2016/en/.

3. Biswas T, Islam A, Rawal LB, et al.: Increasing prevalence of diabetes in Bangladesh: a scoping review. Public Health. 2016, 138:4-11. 10.1016/j.puhe.2016.03.025

4. Akter S, Rahman MM, Abe SK, et al.: Prevalence of diabetes and prediabetes and their risk factors among Bangladeshi adults: a nationwide survey. Bull World Health Organ. 2014, 92:204-213. 10.2471/BLT.13.128371

5. Sayeed MA, Khanam PA, Hussain MT, et al.: Diabetes and hypertension in a Santhal tribe in Bangladesh: a population-based study. J Diabetes Mellitus. 2014, 4:133-140.

10.4236/jdm.2014.42020

6. Wee HL, Li SC, Cheung YB, et al.: The influence of ethnicity on health-related quality of life in diabetes mellitus: a population-based, multiethnic study. J Diabetes Complications. 2006, 20:170178. 10.1016/j.jdiacomp.2005.06.010

7. Biharis of Bangladesh. World Directory of Minorities: South Asia. 2008, Accessed: January 11, 2018: http://www.faqs.org/minorities/South-Asia/Biharis-of-Bangladesh.html.

8. Bangladesh's forgotten students: the Biharis struggle. Global Post PRI Publications. 2010, Accessed: January 11, 2018: https://www.pri.org/stories/2010-07-17/bangladeshs-forgotten-students-biharisstruggle.

9. Wild S, Roglic G, Green A, et al.: Global prevalence of diabetes: estimates for the year 2000 and projections for 2030. Diabetes Care. 2004, 27:1047-1053. 10.2337/diacare.27.5.1047

10. Bozdogan H: Model selection and Akaike's information criterion (AIC): the general theory and its analytical extensions. Psychometrika. 1987, 52:345-370. 10.1007/BF02294361

11. Definition and diagnosis of diabetes mellitus and intermediate hyperglycaemia . WHO Library Cataloguing-in-Publication Data. 2006, Accessed: January 11, 2018: http://www.who.int/diabetes/publications/Definition\%20and\%20diagnosis\%20of\%20diabetes_new.pc

12. Williams DR: Race and health: basic questions, emerging directions. Ann Epidemiol. 1997, 7:322333. 10.1016/S1047-2797(97)00051-3

13. Ford ES, Li C, Pearson WS, et al.: Trends in hypercholesterolemia, treatment, and control among United States adults. Int J Cardiol. 2010, 140:226-235. 10.1016/j.ijcard.2008.11.033

14. Golden SH, Brown A, Cauley JA, et al.: Health disparities in endocrine disorders: biological, clinical, and nonclinical factors--an Endocrine Society scientific statement. J Clin Endocrinol Metab. 2012, 97:1579-1639. 10.1210/jc.2012-2043

15. Spanakis EK, Golden SH: Race/ethnic difference in diabetes and diabetic complications . Curr Diab 
Rep. 2013, 13:814-823. 10.1007\%2Fs11892-013-0421-9

16. Yoon KH, Lee JH, Kim JW, et al.: Epidemic obesity and type 2 diabetes in Asia. Lancet. 2006, 368:1681-1688. 10.1016/S0140-6736(06)69703-1

17. Connolly V, Unwin N, Sherriff P, et al.: Diabetes prevalence and socioeconomic status: a population-based study showing increased prevalence of type 2 diabetes mellitus in deprived areas. J Epidemiol Community Health. 2000, 54:173-177. 10.1136\%2Fjech.54.3.173

18. Brancati FL, Whelton PK, Kuller LH, et al.: Diabetes mellitus, race, and socioeconomic status. A population-based study. Ann Epidemiol. 1996, 6:67-73. 10.1016/1047-2797(95)00095-X

19. Harrison TA, Hindorff LA, Kim H, et al.: Family history of diabetes as a potential public health tool . Am J Prev Med. 2003, 24:152-159. 10.1016/S0749-3797(02)00588-3

20. Standards of Medical Care in Diabetes-2014. Diabetes Care. 2014, 34:11-61. 10.2337/dc14-S014

21. Bays HE, Chapman RH, Grandy S, et al.: The relationship of body mass index to diabetes mellitus, hypertension and dyslipidaemia: comparison of data from two national surveys. Int I Clin Pract. 2007, 61:737-747. 10.1111\%2Fj.1742-1241.2007.01336.x

22. Seidell JC, Han TS, Feskens EJ, et al.: Narrow hips and broad waist circumferences independently contribute to increased risk of non-insulin-dependent diabetes mellitus. J Intern Med. 1997, 242:401-406. 10.1046/j.1365-2796.1997.00235.x

23. Casagrande SS, Whitt-Glover MC, Lancaster KJ, et al.: Built environment and health behaviors among African Americans: a systematic review. Am J Prev Med. 2009, 36:174-181. 10.1016/j.amepre.2008.09.037

24. Lovasi GS, Hutson MA, Guerra M, et al.: Built environments and obesity in disadvantaged populations. Epidemiol Rev. 2009, 31:7-20. 10.1093/epirev/mxp005

25. Gary TL, Safford MM, Gerzoff RB, et al.: Perception of neighborhood problems, health behaviors, and diabetes outcomes among adults with diabetes in managed care: the Translating Research Into Action for Diabetes (TRIAD) study. Diabetes Care. 2008, 31:273-278. 10.2337/dc07-1111

26. Carr MC, Brunzell JD: Abdominal obesity and dyslipidemia in the metabolic syndrome: importance of type 2 diabetes and familial combined hyperlipidemia in coronary artery disease risk. J Clin Endocrinol Metab. 2004, 89:2601-2607. 10.1210/jc.2004-0432

27. Will JC, Galuska DA, Ford ES, et al.: Cigarette smoking and diabetes mellitus: evidence of a positive association from a large prospective cohort study. Int J Epidemiol. 2001, 30:540-546. 10.1093/ije/30.3.540

28. Holbrook TL, Barrett-Connor E, Wingard DL: A prospective population-based study of alcohol use and non-insulin-dependent diabetes mellitus. Am J Epidemiol. 1990, 132:902-909. 10.1093/oxfordjournals.aje.a115733

29. Robbins JM, Vaccarino V, Zhang H, et al.: Socioeconomic status and type 2 diabetes in African American and non-Hispanic white women and men: evidence from the Third National Health and Nutrition Examination Survey. Am J Public Health. 2001, 1:76-83. 10.2105/AJPH.91.1.76 